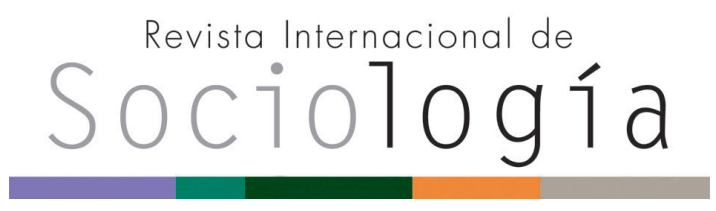

Revista Internacional de Sociología RIS

vol. 78 (3), e159, julio-septiembre, 2020, ISSN-L:0034-9712

https://doi.org/10.3989/ris.2020.78.3.20.116

\section{SOBRE "LA ESTRUCTURA SOCIAL DE LA LIBERTAD" Y OTROS TRABAJOS DE SALVADOR GINER}

\author{
MANuel PÉrez Yruela \\ Instituto de Estudios Sociales Avanzados (IESA-CSIC) \\ mpyruela@iesa.csic.es \\ ORCID iD: https://orcid.org/0000-0002-0875-0688
}

Cómo citar este artículo / Citation: Pérez Yruela, M. 2020. "Sobre "La estructura social de la libertad" y otros trabajos de Salvador Giner". Revista Internacional de Sociología 78(3): e159. https://doi.org/10.3989/ris.2020.78.3.20.116

\section{ON "THE SOCIAL STRUCTURE OF LIBERTY" AND OTHER WORKS BY SALVADOR GINER}

Copyright: @ 2020 CSIC. Este es un artículo de acceso abierto distribuido bajo los términos de la licencia de uso y distribución Creative Commons Reconocimiento 4.0 Internacional (CC BY 4.0).

Recibido: 02/03/2020. Aceptado: 06/05/2020. Publicado online: 28/09/2020

\section{Abstract}

This article pays tribute to Salvador Giner, sociologist and social philosopher, author of a very broad and varied body of work that has marked Spanish sociol-ogy over the last fifty years. The theme of liberty and its social structure has been selected for the impor-tance it has within his work and for the originality with which he treats it. In this work it is analyzed how Giner focuses and develops both aspects within the frame-work of his intellectual biography and the sociological debates of which the social structure of freedom forms part. This theme also shows the importance that he has always attached to the role of citizens in changing and improving their living conditions in society, one of the ways in which the moral dimension of sociology can be specified.

\section{KEYWORDS}

Liberty; Moral philosophy; Situational logic; Sociological theory; Spanish sociology; Structuralism.
Estructuralismo; Filosofía moral; Libertad; Lógica situacional; Sociología española; Teoría sociológica. 
El hombre de hoy se encuentra cada vez más a menudo en un universo donde, quizás por primera vez en la historia, los términos estructura social y libertad humana han dejado de ser forzosamente incompatibles.

(S. Giner, 1971).

\section{INTRODUCCIÓN}

La obra de Salvador Giner es muy amplia y son muy variados los temas que ha tratado en los cuarenta y ocho libros y casi trescientos cincuenta artículos científicos y capítulos de libros que nos ha legado. Él prefiere llamar al conjunto de los dos últimos estudios y ensayos ${ }^{1}$, tal vez para dejar constancia de que él, como ha dicho más de una vez, es un sociólogo dual. Yo así lo creo y, además, añado que creo que lo es en un doble sentido.

El primer sentido se manifiesta en las partes de su obra en las que con frecuencia transita de la sociología a la filosofía social y moral, y viceversa. O establece un diálogo entre ambas. En otras palabras, se expresa cuando, en la observación y análisis de la sociedad, mezcla la mirada y el método del científico social con la del filósofo humanista. Es una primera dualidad que Giner sostiene con su reiterada convicción e insistencia en que la sociología tiene una dimensión moral, en el sentido de que su contribución a la mejora de las condiciones de vida de la humanidad ha de formar parte y ser uno de los objetivos de su quehacer ${ }^{2}$. Por ello, tiene que habérselas a la vez con ambos enfoques, el que atiende a la realidad que es y el que atiende a si es posible y cómo acercarla a la realidad más decente que querríamos que fuera. En su preocupación por el tema de la libertad, que será el objeto principal de este texto, encontraremos pruebas que avalan esta apreciación.

El segundo sentido se expresa en otra de las características que definen su extensa obra. Cuando tuve el honor de hacer su laudatio en el acto en el que le dieron el Premio Nacional de Sociología y Ciencia Política, dije que uno de los comentarios más generosos que había oído sobre su obra era que, cuando algún científico social español se acercaba a un tema que creía nuevo, Salvador Giner ya había pasado por allí, ya había dicho algo sobre él ${ }^{3}$. Es un comentario exagerado, que quien lo dijo lo hizo a sabiendas para reforzar o hacer más visible su argumento, como es frecuente en estos casos. No obstante, el argumento de fondo era a mi juicio cierto, aunque su formulación fuera exagerada. Una parte no pequeña de la obra de Salvador Giner está Ilena de observaciones, intuiciones, asertos, hipótesis, interpretaciones y explicaciones tentativas sobre los muchos temas de los que ha escrito o ha conferenciado. Es la parte que podríamos llamar ensayística de su obra, en la que ha dejado pistas y señales para que otros sigan la indagación, aprovechando la siembra que él ya había hecho. En qué medida se hayan se- guido estas pistas es asunto ajeno a este texto, pero aprovecho la ocasión para expresar el buen deseo, por no decir un brindis al sol, de que nuestra comunidad sociológica se ocupe más de lo que hasta ahora ha hecho por acumular conocimiento a partir del legado de los que aquí nos precedieron y nos enseñaron, siempre que lo valga y lo merezca. Tal vez no sea tan vasto como el que hay en otros países, pero lo hay.

Otra parte de su obra, que va más allá de estas aportaciones seminales, es la que trata de forma sistemática $\mathrm{y}$, hasta donde es posible, completa sobre cuestiones importantes de historia de la sociología y teoría sociológica, tanto conceptuales y metodológicas como analíticas y explicativas. Esta parte constituye lo que podemos llamar sus estudios o investigaciones sociológicas, su otra faceta como sociólogo dual. Me refiero a temas como la sociedad masa, el progreso de la conciencia sociológica, la sociedad corporativa, la lógica situacional, la religión civil o la estructura social de Cataluña, por poner algunos ejemplos.

Creo que su aportación sobre la libertad y su estructura social, una de las que abordó primero en su biografía intelectual, participa de las dos características con que acabo de clasificar su obra. La componen varios estudios y ensayos. Además, me atrevo a decir que esta elección temprana del tema es una señal de la importancia que siempre le concedió al papel que tiene el análisis de la libertad y de su estructura social en desvelar y desplegar el potencial que tiene la ciudadanía a la hora de cambiar y mejorar sus condiciones de vida en la sociedad, una de las formas en que se puede concretar la dimensión moral de la sociología.

Mi objetivo aquí es analizar el artículo en el contexto de otras obras suyas en las que también trata ese tema, así como resumir e interpretar su pensamiento en torno a él y hacer algunas observaciones sobre cómo lo enfoca y desarrolla, en el marco de su biografía intelectual y de los debates sociológicos de los que la estructura de la libertad forma parte.

\section{LA OBRA DE SALVADOR GINER SOBRE LA LIBERTAD Y SU ESTRUCTURA SOCIAL}

El tratamiento que hace Giner del tema no se reduce solo al artículo de 1980. Antes, en 1971, ya había publicado un libro breve en catalán con el título L'estructura social de la llibertat (Giner 1971). En el artículo amplía y desarrolla algunos de los problemas que había introducido en ese libro, como reconoce en una nota a pie de página. Es, por cierto, el tercer libro en la secuencia temporal de sus publicaciones, después de las primeras ediciones de sus muy conocidas y reeditadas Historia del pensamiento social (Giner 1967) y Sociología (Giner 1968). 
Para entenderlo en su completud, hay que tener en cuenta, además, otras aportaciones suyas relacionadas directa o indirectamente con él. Me refiero a los siguientes trabajos, que creo que son los más relevantes, sin perjuicio de que se encuentren referencias en otras de sus obras. Primero, el artículo Para hacer sociología (Giner 1976), en el que explicita, en forma de aseveraciones o postulados, los supuestos básicos con los que practica su oficio de sociólogo. Los agrupa en tres categorías: postulados sobre el método de la sociología, postulados sociológicos sobre la naturaleza humana y postulados sobre la naturaleza de la sociedad. Dice hacerlo sin ánimo de exhaustividad, reconociendo que tienen el carácter de conjeturas y con el objetivo de desvelarlos para el conocimiento, escrutinio y crítica de los demás. Se trata de una iniciativa difícil, arriesgada y, por eso, valiente, que pocos han repetido. Entre esos postulados hay varios que se relacionan con el tema que nos ocupa.

Segundo, el libro El destino de la libertad (Giner 1987b), que fue Premio Espasa-Calpe de Ensayo en 1987, en el que, entre otras cosas, analiza la libertad como una de las tendencias de cambio de mayor importancia, junto a la igualdad, en el proceso de modernización. A la vez, analiza las dificultades que encuentra la realización de la libertad humana en los obstáculos surgidos de los efectos queridos y no queridos de ese proceso, en el que, según él, la libertad encontró en principio las mejores condiciones para avanzar.

Tercero, su trabajo sobre la Estructura social de la libertad republicana (Giner 2002), del que posteriormente hizo algunas revisiones con ligeras modificaciones. Aunque la afinidad de Salvador Giner con el republicanismo es más antigua, este trabajo surgió al hilo del eco que tuvo la obra Republicanismo, una teoría sobre la libertad y el gobierno de Philip Pettit (1999). El eco se debió a que aportaba una forma de entender la libertad, la libertad como ausencia de dominación, que añadía una tercera concepción de libertad a la versión de Isaiah Berlin (1958), hasta entonces considerada canónica, que solo tenía en cuenta dos: las de libertad negativa y libertad positiva, la libertad de ser "libre de" y la libertad de ser "libre para"4. Le llamó libertad republicana porque la formulación de su contenido se derivaba de la tradición histórica, filosófica y política del republicanismo. La idea de libertad como no dominación tenía implicaciones políticas importantes, lo que aumentó el eco de la propuesta. Como se recordará, Pettit asesoró a José Luis Rodríguez Zapatero e inspiró algunas de sus políticas de igualdad. En su trabajo sobre la libertad republicana, Giner analizó las condiciones sociales para su aplicación práctica, concluyendo, como lo hiciera en el Destino de la libertad, que algunas tendencias de la modernidad (corporatismo, burocracia, monopolios y oligopolios...) eran un obs- táculo prácticamente insalvable para que la noción de libertad republicana, como la proponía Pettit, pudiera realizarse.

Cuarto, para acabar de comprender su visión de la libertad y de su estructura social hay que tener en cuenta sus trabajos sobre lógica situacional. Ha publicado varias versiones, la primera en 1977 (Giner 1977), aunque la versión más acabada la publicó en 1997 con el título Intenciones humanas, estructuras sociales: para una lógica situacional (Giner 1997). Creo que se trata de una de sus aportaciones más importantes. Aborda en ella un problema difícil de resolver en las ciencias sociales, creo que irresuelto todavía de manera definitiva: la explicación de la acción social, objeto central de la sociología, que integre la dimensión subjetiva e individual de la acción, la perspectiva del agente, y los condicionamientos y restricciones que la estructura social impone al sujeto que actúa dentro de ella. En esa obra, reivindica la lógica situacional como una de las estructuras latentes de la sociología, idea que analizó en El progreso de la conciencia sociológica (Giner 1974). De acuerdo con esta perspectiva, sostiene que desde los clásicos se han ido acumulando intentos para resolver esta cuestión a través de una tercera vía, que evitara las carencias que para hacerlo tienen tanto el individualismo metodológico, producto de la eclosión del liberalismo, como el holismo o estructuralismo, más frecuente en los comienzos de la teoría sociológica ${ }^{5}$. Critica que la idea de la lógica situacional se haya atribuido a Karl Popper y a su orientación exclusivamente individualista, por el hecho de haber sido él quien la expusiera de manera explícita y reconocible, aunque muy incompleta. La lógica situacional es la teoría que propone Salvador Giner para explicar las relaciones entre estructura social y libertad, sobre la que volveremos más adelante.

\section{El enfoque y el tratamiento DEL TEMA ${ }^{6}$}

En el artículo Para hacer sociología, se encuentran algunos postulados o enunciados que subyacen al enfoque que Salvador Giner dará al tema de la libertad y su estructura social. Los que tienen más relación con él son, resumidos, los siguientes: i) los hombres están dotados de una fuerte tendencia a maximizar su satisfacción subjetiva y su status y bienestar subjetivos, según lo permitan los recursos disponibles; ii) los hombres poseen con intensidad variable una tendencia hacia la conducta altruista, que se manifiesta en su solidaridad afectiva con la condición de los demás; iii) los mitos, conciencia, carisma y lazos comunitarios son esenciales para el mantenimiento de la cohesión social y para reforzar y fomentar la conducta solidaria; iv) los lazos comunitarios obedecen a una necesidad afectiva primordial que coexiste en tensión o conflicto con las estructuras de desigualdad, poder y diferenciación interna de 
cada sociedad; v) el esfuerzo por ser libre mediante la innovación es específico de los miembros de la raza humana; vi) la indagación de los determinantes de la conducta es una práctica de la libertad; vii) la libertad posee una estructura social (Giner 1976: 347-351 y 354).

Creo que estos postulados y la forma en que se reflejan en el análisis de la libertad y de su estructura social responden, en alguna medida, al contexto de su propia biografía intelectual. Se formó como sociólogo en la tradición de los clásicos del pensamiento social (Durkheim, Pareto, Simmel, Tönnies y Weber), como dejó constancia en su Historia del Pensamiento Socia ${ }^{\top}$ y, más recientemente, en su Teoría sociológica clásica (Giner 2001). De ella heredó el postulado de que la sociología tiene como objeto la explicación causal de la conducta, que es intencional y subjetiva. También heredó la asunción de que la sociología reconoce las cualidades relativamente sistémicas de la estructura social y sus efectos condicionantes y, hasta en algunos casos, determinantes de las acciones de hombres y mujeres. Finalmente, el postulado de que la explicación sociológica es pluricausal. Vivió la etapa de auge del estructuralismo en su versión funcionalista y marxista. También vivió la irrupción en ese debate del liberalismo y del individualismo metodológico, en contacto directo o indirecto con algunos de sus principales defensores, entre otros, Karl Popper (Giner inició su carrera académica en Inglaterra cuando Popper estaba de catedrático en la LSE), Friedrich Hayek (Giner lo tuvo como profesor en Chicago) e Isaiah Berlin (Giner tuvo ocasión de presentarle su visión triádica de la libertad en un encuentro que mantuvieron en su casa de Oxford en 1992). Finalmente, fue testigo del ocaso del determinismo estructuralista. En ese debate, nunca fue estructuralista ni individualista metodológico. Si alguna etiqueta se le pudiera poner me atrevo a decir que sería la de conflictivista y weberiano-simmeliano. Lo último por su enfoque de la acción social y de su explicación mediante la lógica situacional. Lo primero por sus postulados sobre la precariedad y conflictividad de todo orden social.

\section{¿Qué es la libertad?}

En su libro L'estructura social de la llibertat (Giner 1971), trata el tema en el contexto del proceso de modernización y de la contradicción entre movilidad social y conflicto de clases en la sociedad industrial, dedicándole el último capítulo a la libertad y a su estructura social. En él fija algunos de los aspectos que mantendrá a lo largo del tiempo en su concepción de la libertad y da una primera definición de ella. Parte de la constatación histórica de que la imputación por la responsabilidad individual de conductas calificadas de punibles es algo común a la mayoría de las comunidades humanas. En todas las sociedades con un grado mínimo de cultura, la libertad existe como principio universal de atribución de responsabilidades individuales, y ese hecho tiene efectos sociales. En este sentido, la libertad es un hecho social constatable. La asunción de esta hipótesis por la sociología era necesaria frente al determinismo de la conducta sobre el que empezó a construirse (Montesquieu, Quetelet, Comte).

Propone una definición de libertad: "la libertad es la acción social consciente y voluntaria en virtud de la cual el hombre transforma de manera altruista una parte de su mundo mejorando la calidad de la vida propia y colectiva" (Giner 1971: 71). Es una definición, inspirada en la de Georges Gurvitch (1963), en la que enfatiza la dimensión transformadora de la libertad. La modificará en su trabajo de 1980. Elimina de su definición la libertad de hacer el mal, de destruir, por ser éstas las acciones que las normas sociales prohíben y sancionan cuando se producen. Por ello, quedan fuera del ámbito de la libertad de acción. No obstante, esto no es suficiente para eliminar el mal en la acción social, tema sobre el que ha vuelto recientemente en su libro Sociología del mal (Giner 2015). Tampoco es suficiente para eliminar el mal como efecto comprobable de la acción social. Muchas acciones que se hacen invocando y prometiendo efectos positivos acaban teniendo efectos negativos y hasta perversos. Esto es frecuente tanto en el ámbito de la ideología, de la política y de otros ámbitos institucionales como en el de las interacciones sociales entre individuos. Por eso dice, "el test sociológico de la libertad como acción social es la comprobación objetiva y crítica de sus efectos" (Giner 1971: 73).

En 1980 amplía el análisis del contexto del que surge su idea de la libertad. Sostiene que, a partir del Renacimiento, la Reforma protestante y el auge del capitalismo, el viejo ideal de la libertad pasa de pertenecer al fuero interno a ser un ideal de libertad hecho posible por la naturaleza misma de la sociedad. Esa visión mundana y europea de la libertad se extendió por todo el mundo. No obstante, cree que desde entonces el "destino de la concepción moderna de la libertad ha sido azaroso, incompleto y, en muchos casos, fallido" (Giner 1980: 8).

Critica que cada movimiento social haya hecho hincapié en aspectos parciales de la presencia de la libertad. Los liberales creen que, estableciendo política y legalmente el espacio de la libertad negativa, la libertad positiva surgirá espontáneamente. No quieren reconocer los obstáculos que para ello suponen las desigualdades de todo tipo que genera el individualismo posesivo y el mercado, ni ver que han dado lugar a los movimientos antiliberales. El socialismo corporativo o de Estado todo lo confía a la planificación, a la propiedad pública o colectiva y a los requisitos burocráticos y de control que su aplicación requiere. No quiere reconocer que esto choca contra los anhelos de libertad de los seres humanos. Final- 
mente, los que practican la visión egoísta, hedonista y subjetiva de la libertad, que creen que es apolítica y aeconómica, la viven cómodamente en los intersticios de la sociedad civil, se marginan socialmente por inhibición y no han logrado establecer un orden social propio (Giner 1980: 12).

Ante estas contradicciones en presencia de la libertad real, concluye que "la búsqueda de una concepción de la libertad que incluya tanto la emancipación de nuestras necesidades elementales como de la opresión y la manipulación social y que al mismo tiempo pare en mientes en la dimensión creativa de nuestra existencia no puede sino conducirnos por derroteros nuevos [...] los que discurren por el terreno de la estructura social [...] como un todo que la va creando en conjunción con las mentes relativamente autónomas de los hombres que la forman" (Giner 1980: 12).

En este texto propone una nueva definición de libertad, con un contenido casi igual al de 1971, pero con otras palabras y con alguna variación importante. La define como "aquella estructura social que fuerza en los hombres a una resolución innovadora de los problemas de su vida sin menoscabar ni sus facultades ni su dignidad humana". La coincidencia estriba en la dimensión transformadora e innovadora de la libertad. La diferencia es que la libertad pasa de ser acción consciente y voluntaria a ser una acción forzada por la estructura social. Este cambio, que modula su postulado de que el esfuerzo por ser libre es específico de los seres humanos, lo justifica por su pesimismo antropológico sobre la voluntad de los hombres por amar la libertad creadora y luchar por ella. Cree que el hombre amará la libertad creadora solo si los valores de su cultura y la necesidad de su situación le impulsan a hacerlo. Por eso, la libertad es un bien precario y requiere un esfuerzo constante de interacción entre la intención humana y la estructura social (Giner 1980: 13-14).

Creo que uno de los aspectos originales y actuales de la visión de Giner sobre la libertad es la dimensión innovadora que le atribuye, asociada a la solución de problemas y conflictos. Se podría decir que la libertad consiste casi únicamente en la innovación, que entiende como la "creación de situaciones sin precedentes para resolver problemas [...] la innovación puede surgir solo en un mundo de problemas a resolver y en el que ni la tradición ni la rutina bastan...". Podemos creernos libres viviendo rutinaria o tradicionalmente, pero solo podremos comprobar que lo somos de verdad cuando la estructura social en la que vivimos nos permita y hasta nos espolee a innovar para superar y resolver conflictos y problemas (Giner 1980: 14). En El destino de la libertad formaliza más esta concepción innovadora de la libertad sosteniendo que hay tres acepciones de ella: la libertad negativa, la libertad positiva y la libertad como innovación y creación de las propias condiciones de vida, una tercera categoría de la libertad a la que también llama libertad como invención (Giner 1987b: 188).

La dimensión moral de la libertad la mantiene en la definición, al decir que de ella no se deriva menoscabo de las facultades ni de la dignidad humana. En cuanto a la compleja relación entre libertad e igualdad, reconoce que el exceso de homogeneización igualitaria puede conducir a la erosión de la libertad, como ya anticipara Tocqueville. No obstante, dado que la igualdad total es imposible y que la vida social es conflictiva, en especial por causa de la desigualdad, esta es un estímulo necesario para la libertad. "Un cierto grado de desigualdad social sería precisamente parte esencial de la estructura social de la libertad", postulado que no hay que entender como justificante de la necesidad de una sociedad esencial y profundamente desigual (Giner 1980: 15).

\section{La estructura social de la libertad}

El postulado de que la libertad tiene una estructura social lo trata desde un punto de vista teórico y desde un punto de vista histórico. El primero lo hace, como dije más arriba, a través de la lógica situacional. La presencia de la libertad en ese análisis es más latente que explícita. La lógica situacional, según Salvador Giner, consiste "en la explicación causal de la acción humana mediante el análisis del proceso que se produce entre las condiciones de vida y las intenciones racionales que la inspiran [...]. Es una explicación de la acción humana intencional según los recursos disponibles" (Giner 1997: 27 y 31).

La lógica situacional parte del imperativo de subjetividad que sostiene que está compuesta por cuatro esferas o ámbitos motivacionales que pueden explicar la acción: las creencias, las necesidades, los intereses y las intenciones. Creencias, necesidades e intereses conforman las intenciones, los objetivos de la acción. También parte de la existencia de un contexto estructural que abre la posibilidad de que los objetivos de la acción puedan alcanzarse, reconociendo que, a la vez, ese contexto los condiciona, los limita, los impide o también los puede crear e impulsar (Giner 1997: 43-46). Finalmente, parte del principio de racionalidad, entendido como adecuación objetiva de la acción a las intenciones que persigue en el contexto, estructura en la que se desarrolla y según los recursos materiales e inmateriales de que el sujeto dispone (Giner 1997: 37-43 y 61-71). Analizar la acción según la lógica situacional es "saber si dada una percepción y conocimiento de la situación el actor o actores que en ella se encuentran se mueven congruentemente con los fines que persiguen" (Giner 1997: 68).

Subraya que, en la medida en que los componentes subjetivos de la acción son muy complejos, y algunos de ellos difíciles de conocer por el observador, 
la racionalidad de la acción no puede reducirse ni simplificarse a un único interés como, por ejemplo, hace la economía política en el caso del homo oeconomicus maximizador de ganancias o hizo el estructuralismo marxista con los intereses de clase. No es que no existan esas racionalidades, sino que no son las únicas que pueden derivarse de la naturaleza humana o de la pertenencia a una clase o estrato social determinado.

La acción racional puede ser producto de otras muchas combinaciones entre elementos subjetivos y estructurales de la acción, amén de la existencia de interacciones condicionantes entre ambas, ya que también sabemos que la estructura condiciona la acción. En otras palabras, hay acciones que pueden parecer poco racionales y hasta irracionales, pero que según la lógica situacional del sujeto que las acomete no lo son. Por eso, añade: "Es menester pues incorporar la conducta pseudoracional a la gran masa del comportamiento racional" (Giner 1997: 67).

Igualmente, subraya que la estructura social en la que se desarrolla la acción, el orden social que crea, no carece de contradicciones ni conflictos y no es cerrado hasta controlar todos los espacios disponibles por los que la acción transformadora e innovadora puede transitar. En otras palabras, que todo orden social es precario e inestable en mayor o menor medida.

Este énfasis en la complejidad y la variedad de la acción social que puede calificarse de racional, y en la relativa precariedad de todo orden estructural, permite concebir la libertad como un proceso interactivo entre intenciones humanas y estructuras sociales, que deviene finalmente en cambio social. Por eso, para Giner "la libertad es una creación histórica de los hombres en producción innovadora de su existencia cuando las condiciones estructurales de las que parten les movilizan en ese sentido" (Giner 1980: 17). Es tarea de la sociología analizar ese proceso, para observar la libertad real que es posible en cada caso. Lo mismo, piensa, se puede aplicar a la sociología en la que la estructura misma del pensamiento sociológico produce las condiciones necesarias para que se genere en él innovación.

Del postulado anterior arranca su análisis historicista de la libertad. Su aportación desde esta perspectiva se limita, por una parte, a citar algunos ejemplos de la historia en los que fue visible el ejercicio de la libertad como innovación: Atenas y Venecia en sus momentos de esplendor; la aparición del fenómeno creativo en las ciencias y las artes de Viena en los peores momentos del ocaso del imperio; o el siglo de oro de las letras españolas en medio de la oscuridad creada por la esclerosis inquisitorial. No cree que estos y otros ejemplos pudieran unirse por un hilo conductor significativo del avance de la libertad innovadora. Más bien son momentos estelares de su aparición entre otros de rutina y sometimiento a las circunstancias.
Por otra parte, constata que la libertad tal como hoy la conocemos en la realidad, junto con el avance de la igualdad, es una de las dos tendencias de cambio profundo más importantes del proceso de modernización de Occidente, idea que desarrolla más en su libro El destino de la libertad (Giner 1987b). La libertad actual ha sido fruto de dos dimensiones de este proceso. Lo ha sido por el proceso de institucionalización de la libertad a través de la consolidación de la ciudadanía en el contexto del Estado de derecho de los Estados nación, que la han reconocido legalmente. Y lo ha sido por el proceso de la tecnificación y especialización del trabajo, en otras palabras, del desarrollo económico, que ha liberado a los hombres de su dependencia de las tareas para la subsistencia y les ha dejado tiempo para ocuparse en otros asuntos y ejercer su libertad. El desarrollo, el imperativo maximizador como él le llama, al que me referiré más abajo, ha ido reduciendo progresivamente estas dependencias, a través de la realización práctica de la idea de Estado social de derecho o de estado de bienestar, que se ha producido sobre todo en los países europeos y que tanto admiran otras gentes.

Hoy, esta última conquista está en una seria encrucijada (Pérez Yruela 2018). Digo esto porque es buen ejemplo de otro de los asuntos que han preocupado a Salvador Giner en su análisis del tema que nos ocupa. Se trata de la relativa precariedad e inestabilidad de algunos logros de la libertad como innovación. Esto se debe a las contracorrientes surgidas del mismo proceso de modernización, que pese a haber alumbrado la estructura social de la libertad más favorable para la realización de ese viejo ideal humano, pueden estar poniendo en peligro su destino.

\section{El destino de la libertad}

La preocupación por el destino de la libertad la ha desarrollado Giner en varios de sus trabajos: en el artículo que es objeto de este comentario, en el libro cuyo título he cogido prestado para este epígrafe y en su trabajo sobre la libertad republicana. En los tres se encuentra una argumentación parecida, obviamente con matices en cada caso. Ha habido muchos análisis sobre las contradicciones y conflictos más importantes entre las diversas tendencias que componen el proceso de modernización. Por ejemplo, entre la libertad y la igualdad. La primera tiende a la apropiación de los bienes y a la creación de desigualdades. Cuando se quiere promover y garantizar la segunda hay que establecer algunas limitaciones a la libertad. También entre sistema capitalista y democracia, ya que se trata de dos ámbitos institucionales con lógicas distintas. El primero basado en la propiedad privada, la jerarquía, la coordinación imperativa y las relaciones difíciles entre los intereses del capital y del trabajo. El segundo en la participación, en la igualdad, en 
el interés general, en la protección de los derechos de los ciudadanos y en sus virtudes cívicas.

Salvador Giner añade a estas contradicciones otras producidas por tendencias más recientes, a las que me voy a referir brevemente y no de forma exhaustiva. Sostiene que alguna, como el imperativo maximizador (Giner 1987b: 86 y ss.), que es el que mueve a la economía capitalista y a la sociedad de consumo, genera escasez de tiempo, de espacio, de trabajo y de recursos naturales y paisajísticos. Su solución, si es que los movimientos sociales con su presión y sus denuncias llegan a conseguirlo, exigirá regulaciones que impondrán necesariamente límites a la libertad.

La corporatización creciente de las sociedades modernas y el crecimiento de la burocracia que la acompaña es otra tendencia cuyos efectos también ponen límites a la libertad ${ }^{8}$. El análisis corporatista del mundo moderno destaca la presencia creciente de grandes organizaciones, con tendencias oligopolísticas y monopolísticas en sus respectivos ámbitos de actuación, sea empresarial, financiero, mediático, cultural, político o sindical. Son actores sociales colectivos, que han sustituido a los actores individuales y pueden ejercer una influencia enorme en la sociedad. La acumulación corporativa que se ha producido en las últimas décadas ha sido extraordinaria. Se ha producido a impulsos del imperativo maximizador y de la tecnología de la información, y lo han facilitado e impulsado los procesos de desregulación de inspiración neoliberal que han hecho posible la concentración empresarial y de otras entidades. Las corporaciones son estructuras jerárquicas en las que el control y la subordinación a los intereses corporativos crean inevitables interferencias con la libertad de quienes forman parte de ellas. A su vez, las corporaciones, especialmente las del ámbito económico de cualquier sector, han generado a su alrededor una buena cantidad de pequeñas entidades, muchas de autónomos, que mantienen relaciones de dependencia con ellas. Para describir este entramado corporativo se ha utilizado a veces la metáfora de una refeudalización de la sociedad, como una manera de visibilizar sus efectos sociales en las asimetrías, dependencias y desigualdades de las relaciones sociales, que entrañan límites a la libertad.

Los argumentos que utiliza Salvador Giner en el análisis de la libertad republicana son muy parecidos $^{9}$. No obstante, en su obra ocupan un lugar muy importante los trabajos sobre la sociedad civil y su autonomía, el reconocimiento de la importancia de la cultura y las virtudes cívicas para la democracia y el fomento de la libertad cívica y la innovación democrática, al margen de las interferencias estatales y gubernamentales. Es un espacio en que la libertad republicana puede materializarse parcialmente, en tensión con los obstáculos que surgen de otras tendencias como las anteriores.
El desarrollo de las tecnologías de la información y las comunicaciones está dando lugar a formas de control e influencia por parte de las grandes operadoras de estas tecnologías de capacidad insospechada para el destino de la libertad. La acumulación y manejo de información a través de lo que se conoce como big data las dotará de nuevas y mejores formas de influencia.

Finalmente, voy a referirme a otra tendencia cuyos efectos se han dejado ver especialmente en la política en los últimos años. La formalización corporatista del mundo no ha eliminado la necesidad que tiene el hombre de lazos comunitarios. Como dijo José Murillo Ferrol en la inauguración de un congreso de Ciencia Política, en memorable aserto, "el hombre es un animal de cercanías" y, añado, pese a que la modernidad haya acortado y comprimido nuestra percepción del espacio y el tiempo, parece que lo sigue siendo. La modernización y la globalización, y la subsiguiente descomposición que han provocado de esos lazos, han creado incertidumbres, desconcierto y hasta anomia entre los ciudadanos. Algunos se quieren proteger de ello buscando refugio en nacionalismos y movimientos sociales en los que, como dice Giner, "florece una visión colectivista, retribalizada y mesiánica de la libertad, profundamente antagónica a la autonomía del individuo [...]. Cuando la retribalización emocional colectiva (nacional o de clase) se encuadra en una corporación política de asalto, la combinación viene a ser de lo más explosivo que conocemos en el mundo de hoy" (Giner 1987b: 24). Acertada premonición del surgimiento de algunos populismos al que hoy estamos asistiendo.

A la vista de estas tendencias y otras que no he señalado por razones de espacio, Giner es pesimista sobre el destino de la libertad. Cree que la modernidad nos puede haber abocado a una situación cuyos problemas solo podrían resolverse "en un orden social jerárquico, cibernético, universalizante, con controles seculares de la vida cotidiana y de los bienes a consumir y a poseer". Pero lo es solo en el condicional de que "de seguir las cosas como van sucederá un ahogo de la libertad [...] todos los casos de libertad y creatividad conocidos son efímeros de cincuenta a ciento cincuenta años a lo sumo" (Giner 1987b: 26). A este pesimismo condicional contrapone su idea de que la libertad como innovación es innata o endémica en el hombre. Además, la nuestra es una sociedad abierta con una estructura social de la libertad que, pese a los límites que acabamos de ver que le impone, permite que los hombres podamos seguir siendo dueños de nuestro destino. Por otra parte, tampoco el futuro está escrito y, pese a las tendencias analizadas, pudiera tomar rumbos diferentes del que estas señalan. Todo esto permite albergar la esperanza de que sigamos haciendo uso de la facultad más afín a la libertad: la razón crítica y secular, así como la invención (Giner 1987b: 27), para cambiar el destino de la libertad que estas tendencias presagian. 


\section{Comentario final}

La cita con la que he encabezado este texto creo que sintetiza bien el enfoque con el que Salvador $\mathrm{Gi}$ ner ha tratado en su obra el problema de la libertad. Su preocupación se ha centrado en trabajar en una explicación de la acción que, por un lado, dejara espacio a la libertad, asumiendo las limitaciones y condicionamientos de la estructura social y que, por otro, tuviera en cuenta la complejidad de las pasiones, intenciones, intereses y creencias que mueven a la acción a los individuos, en el marco de las circunstancias o la estructura en la que actúan. La libertad que surge de ese espacio, de esa situación, es para Giner algo más que la libertad negativa o positiva del liberalismo. No es tampoco la libertad como no dominación del republicanismo, aunque se acerca más a ella. Tampoco es la libertad del colectivismo. Es una libertad transformadora, creativa e innovadora, palabra esta última hoy tan de moda que, como hemos visto, utiliza con frecuencia en el desarrollo de sus ideas. Es una libertad que nos hace protagonistas a los ciudadanos del cambio social, para bien y para mal, y nos interpela como responsables en última instancia de que, a partir de ella, sigamos buscando y aplicando soluciones innovadoras a los problemas que nos acucian. Una libertad de la que también nos recuerda la facilidad con la que podemos renunciar a ella y optar por plegarnos cómodamente a las presiones y condicionamientos estructurales.

Pero, sobre todo, se trata de una libertad que solo puede materializarse en ciertas condiciones ambientales, en ciertas estructuras sociales entre cuyos intersticios y contradicciones puede florecer. Es una libertad real, concreta y comprobable, que es posible en cada estructura social y no una libertad absoluta, utópica o idealista. La libertad total no existe y la promesa de una libertad-ficción de esa naturaleza devendría en el mayor fiasco para quienes se dejaran embaucar por tal promesa.

La libertad es hija del esfuerzo, de la constancia y del interés por preservarla y acrecentarla, aun a sabiendas de que el avance es lento y su destino siempre frágil e inestable. Es igualmente hija del conflicto, porque son los conflictos sociales de todo tipo los que mueven a los hombres a buscar soluciones innovadoras que, con más o menos acierto, traten de resolverlos, modificando, mejor o peor, los elementos de la estructura social que los producen, en una secuencia continuada que, aunque parezca grandilocuente, es nuestra historia y la historia de la libertad. Y es hija también del impulso moral que nos lleva a abrazarla para defender valores y cambios en la estructura que creemos que mejorarán nuestra situación y la de nuestros semejantes.

Su aportación es una enmienda a la idea de libertad del liberalismo, sin negar el valor de lo que esta corriente ha significado para su conquista. Una enmienda de la que se derivan implicaciones importantes, ya que la solución del conflicto entre libertad e igualdad no se puede resolver solo con más libertad. Tendría que resolverse con reformas, con innovaciones de la estructura social que promuevan la igualdad suficiente para que todos puedan disfrutar también de una libertad equiparable.

El mensaje para los que practicamos la sociología es que trabajemos en el análisis concreto de las estructuras sociales bajo la perspectiva de su relación con la libertad. Que estudiemos los resultados de tantas promesas y decisiones que, invocando la mejora de las condiciones de vida de los ciudadanos, terminan por producir efectos contrarios. Que estemos atentos a la lógica tergiversadora de la historia para anticipar que el destino de la libertad siga caminando hacia buen puerto, a pesar de que los efectos no queridos y adversos de muchas tendencias y proyectos amenacen con impedirlo.

Es seguro que no todos los que practican esta disciplina estarán de acuerdo con ese mensaje. Pero es una prueba más de lo que el sociólogo, filósofo y humanista Salvador Giner lleva diciendo tanto tiempo, que la sociología es una disciplina, no la única, que tiene una dimensión moral.

\section{REsPuesta AL COMENTARIO QUE MANUEL Perez YRUela hace de MI LABOR, EN EL TEXTO "SOBRE LA ESTRUCTURA SOCIAL DE LA LIBERTAD Y OTROS TRABAJOS DE SALVADOR GINER"}

\section{Salvador Giner}

La vivencia de que sea un amigo íntimo quien se enfrente a la tarea de comentar y evaluar la propia obra es muy nueva para mí, pues en el caso que me ocupa no se trata de una mera laudatio ceremonial, sino de un esfuerzo riguroso. El profesor Manuel Pérez Yruela analiza mi ensayo La estructura social de la libertad con singular acierto. He aquí algunos comentarios a su generoso escrito.

Hay en el escrito de mi amigo más exhuberantia cordis de la que habría si sus observaciones no las hubiera compuesto él. Pero, como también hay serenidad y mucha profesionalidad en su análisis, es obligado por mi parte responder a sus observaciones. Manan también de su condición como ingeniero agrónomo, sociólogo rural de original aportación y director durante largo tiempo de un renombrado instituto de Investigación en ciencia social (IESA-CSIC). Su descollante competencia en el campo de la teoría social, así como en el de la sociológica, se percibe en todas sus consideraciones.

Su escrito concentra su atención sobre mi tratamiento de la libertad humana. Al así hacer, deja de 
lado, muy legítimamente, otros campos en los que he trabajado con mayor o menor fortuna, como son la sociedad española, la evolución sincrónica de los países de la Europa meridional, la historia de la teoría social y la crítica de la visión reaccionaria y antidemocrática de sociedad moderna como sociedad masa o de masas, amén de los trabajos sociológicos empíricos en los que me he visto, hasta hoy mismo, implicado de hoz y coz. Que algunos tengamos inclinaciones teóricas manifiestas y nos sintamos atraídos por la filosofía, especialmente la moral, no nos exonera de trabajar como peones, realizar encuestas, acumular datos, interpretarlos.

Un comentario de la índole del suyo no tiene por qué reproducir con pormenor lo que considera. Así, su referencia a mi tratado El progreso de la conciencia sociológica no define lo que entiendo como avance de tal conciencia, y deja que el curioso lector se zambulla en mis diversos escritos en los que he tratado la cuestión de cómo el conocimiento sociológico del mundo humano ha ido avanzando desde la aparición de una conciencia del mismo, hasta hoy. El origen remoto puede buscarse en el sabio de ascendencia andalusí Abén Jaldún, pero la línea, sin solución de continuidad, va desde Montesquieu hasta hoy. A mi juicio, culminó en Parsons, Shils y Merton, inmediatamente tras Mannheim y algún otro, cosa a la que mi comentarista alude, aunque no me parece que discrepe. Tampoco discrepa de mis ataques y descalificaciones a formas perversas de la teoría social, como las representadas por el otrora vastamente popular Louis Althusser, expresadas contra viento y marea en el momento en que mayor público entusiasta tenían en Francia, Inglaterra y clamorosamente en España.

Muy de agradecer es que, en su búsqueda de mi propia concepción de la libertad, el profesor Manuel Pérez Yruela identifique como significativo mi intento de superación de la concepción, binaria, de la libertad puesta célebremente en circulación por Isaiah Berlin. Y cuestionada por mi propia visión, triádica, del asunto, mucho antes de mi larga conversación en su casa en Oxford, de la que dio fe alguna publicación española, incluso un periódico. Mi esforzado observador dice, correctamente, que mi propuesta considera tres suertes de libertad, la positiva, la negativa y, finalmente, la creadora. Me parecería más adecuado llamar a la última creativa (sin caer en el machacón concepto tan de moda hoy de hablar de algo tan nebuloso como lo de la creatividad, que invade el lenguaje de hoy y hasta la charlatanería y ruido ambiental que nos rodea.) En cambio, su énfasis en la importancia, en mis escritos, de la innovación, es adecuado. Me encantaría que algún lector se fijara en mis ideas, en escorzo sobre cómo la estructura misma del pensamiento sociológico produce las condiciones necesarias para que se genere en él innovación y, por tanto, progreso.
Suele sorprenderme el hecho de que mi propuesta de un conjunto de postulados sobre la naturaleza humana y su relevancia para la sociología y todas las ciencias sociales, desde la historia a la antropología, pasando por la economía política, haya sido pasada por alto por cuantos han considerado mi obra, excepto en este texto al que me estoy refiriendo. No puede atribuirse ello a que apareció por vez primera en una revista filosófica poco o nada consultada por los de mi gremio, puesto que con terquedad he incluido esos postulados hasta en mi modesta introducción a la sociología, de la que no puedo quejarme que haya sido ignorada, ni aquí ni en los más diversos lugares en que ha aparecido, me dicen que bien traducida a varias lenguas.

Las diferentes referencias que hace a mi republicanismo, del que soy entusiasta a fuer de liberal muy escorado hacia la izquierda, son de agradecer y, a mi juicio, correctas, salvo a que la une a los trabajos de Philippe Pettit, obra que en un momento tuvo notable audiencia en España. Sin que ello sea erróneo, cabría recordar que mi interés por el republicanismo es autónomo. Detecté sus raíces hasta en el mayor pensador político catalán de todos los tiempos, Francesc Eiximenis, en su inmortal Regiment de cosa pública. Por feliz coincidencia, Pettit por su parte también identificó en el Renacimiento, en Maquiavelo, las raíces históricas del republicanismo. Como sociólogos no debería sorprendernos que ambas teorías políticas surgieran en el Mediterráneo casi coetáneamente con experiencias similares de gobierno semidemocrático por parte de ciudadanos y patricios cívicos, en Valencia, Barcelona, Florencia y Pisa, entre otros lugares. La alusión a mi autonomía respecto a la obra de Pettit no intenta disminuirla.

Por otra parte, cuando echo un vistazo a lo que suele llamarse el currículum me percato del volumen que ocupan mis trabajos sobre la sociedad civil, su autonomía y, de nuevo, su fomento de la libertad cívica y de la innovación democrática, al margen de las interferencias estatales y las impertinencias gubernamentales, tan connaturales a los gobiernos de la derecha y tan perniciosas si vienen de la izquierda, que debería por definición ser tan amiga de la libertad cívica como de la igualdad en la distribución de recursos entre la ciudadanía. Finalmente, una observación sobre mi exploración de la lógica situacional.

El profesor Pérez Yruela ve en ella un esfuerzo por hallar un modo de desentrañar el comportamiento humano expresado en lo que los sociólogos entendemos por acción, o acción social, por lo menos desde Weber o, según mi opinión, desde Simmel también. Tal vez, como no tengo nada que matizar y, menos, que discrepar con él, debería callar.

Pero hasta en la aprobación hay necesidad de réplica a veces. Uno querría ver una restauración de la importancia de la visión weberiano-simmeliana de la acción en la filosofía social de hoy, en demasía orien- 
tada a los efectos de la innovación tecnológica sobre nuestro mundo y cada vez más alejada de quienes deberían seguir estimulando nuestras neuronas, como Schopenhauer y algún otro. Ya que mi amable crítico subraya mis debilidades por los clásicos, e incluso las encuentra recomendables -él mismo es ducho en esas lides-, desearía brindar a los dioses inmortales para que ningún sociólogo con mínima ambición intelectual dejara de zambullirse en ellos.

En tal caso, hasta el más superficial estudio sociológico, basado en acopio de datos, sondeos y encuestas, mejoraría en relevancia y en la inmediatez y utilidad pública de sus resultados.

\section{NOTAS}

1. Así lo hace en su lista oficial de publicaciones. Este documento se conserva en el IESA-CSIC junto al Fondo Bibliográfico Salvador Giner, donado por él, que reúne un ejemplar de casi todos sus trabajos. A estas aportaciones hay que añadir unas cuatrocientas cincuenta más, la mayoría no recogidas en el Fondo, que son traducciones y reseñas de libros, y artículos y entrevistas publicadas en prensa diaria y revistas.

2. Sobre esto puede verse su ensayo "Sociology and Moral Philosphy” (Giner 1987a) así como una versión revisada en castellano (Giner 2000).

3. Este comentario lo hizo el profesor Félix Ovejero, en su intervención en el homenaje que tributamos un grupo de amigos y colegas a Salvador Giner en la sede del IESA-CSIC en Córdoba, en marzo del año 2005.

4. Fue la conferencia inaugural del curso 1958/59 de la Universidad de Oxford, publicada ese mismo año por Clarendon Press (Berlin 1958). Posteriormente, se incluyó en la obra Four Essays on Liberty, publicada en 1965 por Oxford University Press, que suele ser la más citada.

5. El intento de una tercera vía entre individualismo metodológico y estructuralismo u holismo ha tenido otros visitantes, como, por ejemplo, el individualismo estructuralista, como se ha llamado a la posición de G. Homans en este asunto, el constructivismo de A. Giddens o la teoría de la elección racional, uno de cuyos exponentes más próximos a la lógica situacional en el ámbito de la sociología es Raymond Bou-

\section{REFERENCIAS BIBLIOGRÁfICAS}

Aguiar, F. 2007. "La teoría de la elección racional: dos logros y cuatro pérdidas". Pp. 75-88 en Escritos Sociológicos. Libro homenaje a Salvador Giner, compilado por M. Pérez Yruela, T. Montagut y T. González de la Fe. Madrid: CIS.

Berlin, I. 1958. Two concepts of Liberty. Oxford: Clarendon Press.

Giner, S. 1967. Historia del Pensamiento social. Barcelona: Ariel.

Giner, S. (1968). Sociología. Barcelona: Península.

Giner, S. 1971. L'estructura social de la llibertat. Barcelona: Edicions 62.
Nada que decir tengo sobre la aseveración de que mi visión de la sociología es que es una disciplina moral. Es acertada y sostenible. En mi ensayo sobre la relación que existe entre sociología y filosofía moral, cuya versión castellana reitera lo que sostenían las inglesas e italianas, insistí en que la filosofía moral de hoy, la ética, es incompleta si es sociológicamente analfabeta. Como es defectuosa toda sociología que sea filosóficamente analfabeta.

Te estoy muy obligado, lector amigo, por haber leído esta escuálida respuesta a lo que, con mayor tino que el mío, ha sabido detectar y analizar mi crítico y amigo, Manuel Pérez Yruela. Laus Deo. Deo sive naturæ. don. Giner dice en el desarrollo de su lógica situacional que se trata de hacer una estructuralización de la acción social para explicarla, que podría ser otra forma de llamar al individualismo estructural. Se trataría de incorporar los efectos de la estructura en la acción. En cualquier caso, lo que sucede en la teoría sociológica es que no se han hecho suficientes esfuerzos para el crecimiento y perfeccionamiento de la teoría por acumulación e integración de aportaciones previas, como, por ejemplo, lo hiciera Parsons con los clásicos, al margen del destino final que tuviera ese esfuerzo. Giner lo ha tratado de hacer con la Lógica situacional y con el Progreso de la conciencia sociológica.

6. Para complementar el análisis que hago en este apartado, pueden consultarse trabajos de otros autores que también lo han analizado y publicado en una obra producto del homenaje que se le tributó en 2005 (Aguiar 2007; Rodríguez lbáñez 2007; Robles y Miller 2007). Este libro homenaje que recoge trabajos sobre la obra de Salvador Giner, incluye además una larga entrevista sobre su biografía intelectual.

7. Se han hecho nueve ediciones de ella, la primera en 1967 (Giner 1967), varias ampliadas, hasta la última en 2008.

8. Para este tema puede verse Giner, S. y M. Pérez Yruela (1979).

9. Sobre esto puede verse también Pérez Yruela, M. (2007).
Giner, S. 1974. El progreso de la conciencia sociológica. Barcelona: Península.

Giner, S. 1976. "Para hacer sociología". Teorema VI/3-4: 343357.

Giner, S. 1977. "Intenciones humanas y estructuras sociales: aproximación crítica a la lógica situacional". Cuadernos Económicos I.C.E. 3-4: 110-145.

Giner, S. y M. Pérez Yruela 1979. La sociedad corporativa. Madrid: CIS.

Giner, S. 1980. "La estructura social de la libertad". REIS 11: 7-27. 
Giner, S. 1987a. "Sociology and Moral Philosphy". Revue International de Sociologie/international Review of Sociology 3: 47-80.

Giner, S. 1987b. El destino de la libertad. Madrid: EspasaCalpe.

Giner, S. 1997. "Intenciones humanas, estructuras sociales: para una lógica situacional”. Pp. 21-126 en Acción Humana, coordinado por M. Cruz. Barcelona, Ariel.

Giner, S. 2000. "Sociología y Filosofía Moral”, Pp. 118-162 en Historia de la Ética. La ética contemporánea. Vol. 3. Editado por Camps, V. Barcelona: Crítica.

Giner, S. 2001. Teoría Sociológica clásica. Barcelona: Ariel. ( $3^{a}$ edición revisada y ampliada en 2011).

Giner, S. 2002. "La estructura social de la libertad republicana". Pp. 65-86 en Retos pendientes en ética y política, compilado por J. Rubio Carracedo, J. M. Rosales y Toscano Méndez, M. Madrid: Trotta.

Giner, S. 2015. Sociología del mal. Madrid: Catarata.

Gurvitch, G. 1963. Determinismes sociaux et liberté humaine. París: P.U.F.
Pérez Yruela, M. 2007. "Republicanismo y corporatismo". Pp. 145-158 en Escritos sociológicos en Homenaje a Salvador Giner, compilado por M. Pérez Yruela, T. Montagut y T. González de la Fe. Madrid: CIS.

Pérez Yruela, M. 2018. "Condiciones y contenido para la renovación de la agenda en torno al bienestar". Pp. 44-73 en Bienestar social y políticas públicas, editado por G. Jaraíz. Madrid: Catarata.

Pettit, P. 1999. Republicanismo, una teoría sobre la libertad y el gobierno. Barcelona: Ariel.

Robles, J. M. y L. M. Miller 2007. "La lógica de la situación: una vuelta más de tuerca". Pp. 325-334 en Escritos Sociológicos. Libro homenaje a Salvador Giner, compilado por M. Pérez Yruela, T. Montagut y T. González de la Fe. Madrid: CIS.

Rodríguez Ibáñez, J. E. 2007. "Un caballero de la libertad. Acotaciones a la relectura de dos textos emblemáticos de Salvador Giner". Pp. 137-144, en Escritos Sociológicos. Libro homenaje a Salvador Giner, compilado por M. Pérez Yruela, T. Montagut y T. González de la Fe. Madrid: CIS.

Manuel Pérez Yruela es Profesor de Investigación (Ad Honorem) en el Instituto de Estudios Sociales Avanzados (IESA), del que fue Director entre 1991 y 2009. Ha mantenido una estrecha relación con el Profesor Salvador Giner, del que se considera: discípulo, fue su tutor entre 1976 y 1979 mientras ampliaba estudios de sociología en el Reino Unido; colaborador en la creación del IESA y en la publicación conjunta de bastantes trabajos, en especial sobre las tendencias corporatistas de las democracias avanzadas); y amigo. El Prof. Pérez Yruela ha trabajado y publicado además sobre temas de sociología rural y del desarrollo; conflicto, cambio y modernización de la sociedad andaluza; pobreza, exclusión social, Tercer Sector y política social; sociología de la ciencia y la tecnología; y sociología política y opinión pública. Ha sido Presidente de la Federación Española de Sociología (2004-2007). 